\section{Commentary: The call of the mild: Aortic insufficiency in patients with left ventricular assist devices}

\author{
Amit Iyengar, MD, MS, and Pavan Atluri, MD
}

There are several proposed mechanisms by which aortic valve insufficiency (AI) may develop or worsen during left ventricular assist device (LVAD) therapy, including annular/sinus dilatation, increased valvular gradients, and leaflet deterioration from changes in flow patterns and shear forces. ${ }^{1,2}$ Although negative hemodynamic effects from circulatory shunt and impaired left ventricular unloading have been demonstrated with neglected AI, only recently have larger, higher-powered studies correlated these mechanistic findings with appreciable clinical detriments. ${ }^{3}$ The threshold at which to intervene has been previously defined by the International Society for Heart and Lung Transplantation at greater than mild (Level 1c recommendation), as aortic valve interventions are not without increased morbidity. ${ }^{4,5}$

In this issue of the Journal, Tanaka and colleagues ${ }^{6}$ reviewed their experience surveilling patients with mild AI after LVAD implantation. They performed a matched cohort study examining their patients with mild AI not intervened on at the time of LVAD implantation compared with those with no/trace AI. They demonstrated equivalent mortality and readmission rates and between their cohorts; however, they noted a significant rate of progression to moderate or greater $\mathrm{AI}$ after 2 years in their mild $\mathrm{AI}$ cohort compared with the no/trace AI group (43.6\% vs $8.9 \%$ ), along with worse concomitant valvular pathology, functional status, and more heart failure readmissions. The authors are to be commended for their dedication to surveilling these patients diligently following their LVAD placement and assessing important clinical outcomes beyond mortality.

\footnotetext{
From the Division of Cardiovascular Surgery, Department of Surgery, Hospital of the University of Pennsylvania, Philadelphia, Pa.

Disclosures: The authors reported no conflicts of interest.

The Journal policy requires editors and reviewers to disclose conflicts of interest and to decline handling or reviewing manuscripts for which they may have a conflict of interest. The editors and reviewers of this article have no conflicts of interest.

Received for publication April 4, 2020; revisions received April 4, 2020; accepted for publication April 6, 2020; available ahead of print April 18, 2020.

Address for reprints: Pavan Atluri, MD, Division of Cardiovascular Surgery, Hospital at the University of Pennsylvania, 3400 Spruce St, 6 Silverstein, Philadelphia, PA 19104 (E-mail: Pavan.atluri@uphs.upenn.edu).

J Thorac Cardiovasc Surg 2020;160:1501-2

$0022-5223 / \$ 36.00$

Copyright (C) 2020 by The American Association for Thoracic Surgery

https://doi.org/10.1016/j.jtcvs.2020.04.034
}

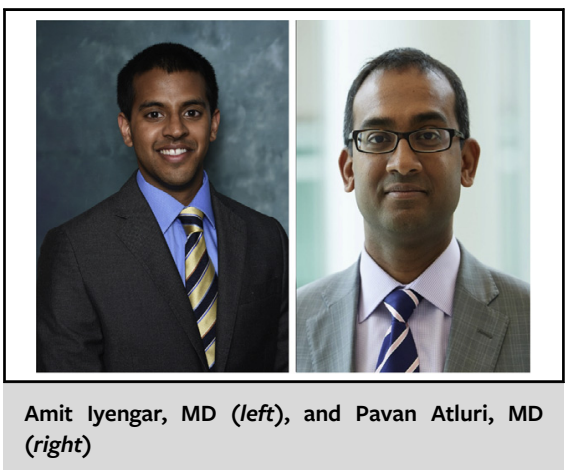

CENTRAL MESSAGE

In a matched retrospective

cohort study, the current au-

thors have demonstrated that

uncorrected mild aortic insuffi-

ciency was associated with

worsened functional status after

LVAD implantation.

The study directly calls into focus our threshold for aortic valve interventions at the time of LVAD implantation. The authors already claim to now more carefully assess intraoperative AI and will proactively perform a Park stitch for all cases of mild AI at the time of LVAD implantation-a departure from guidelines but a strategy that some surgeons elsewhere are also employing. Although we do not necessarily agree with Park stiches for all cases of mild AI, it is certainly a reasonable approach for many patients. Traditional surgical aortic valve replacement (AVR) may be a more durable and nearly-as-simple procedure to perform in cases with poorquality aortic valve tissue. The steady improvement in LVAD survival and outcomes with device innovation undoubtedly calls for a more careful re-examination of guidelines, as our patient population may now be surviving to see the morbidity from AI progression. Although surgical AVR can certainly be performed in patients with preexisting LVAD implants, there is a clearly defined morbidity associated with this delayed correction. Transcatheter AVR remains undefined in patients with VADs and remains a therapy used for aortic stenosis in mainstream use. ${ }^{2}$ Functional status, heart failure readmissions, and the impact on right ventricular function and other valvular lesions will need to be considered as more patients are receiving implants for destination or bridge-to-decision indications. As we focus on these more granular outcomes in our patients with LVADs, we are beginning to hear the "Call of the Mild," suggesting 
for a more aggressive approach to optimizing the aortic valve. We look forward to additional studies regarding the impact of more subtle valvular lesions in this growing patient cohort.

\section{References}

1. Yoshida S, Toda K, Miyagawa S, Yoshikawa Y, Hata H, Yoshioka D, et al. Impact of turbulent blood flow in the aortic root on de novo aortic insufficiency during continuous-flow left ventricular assist device support. Artif Organs. February 21, 2020 [Epub ahead of print].

2. Noly PE, Pagani F, Noiseux N, Stulak JM, Khalpey Z, Carrier M, et al. Continuous-flow left ventricular assist devices and valvular heart disease: a comprehensive review. Can J Cardiol. 2020;36:244-60.
3. Truby LK, Garan AR, Givens RC, Wayda B, Takeda K, Yuzefpolskaya M, et al. Aortic insufficiency during contemporary left ventricular assist device support: analysis of the INTERMACS registry. JACC Heart Fail. 2018;6: 951-60.

4. Robertson JO, Naftel DC, Myers SL, Prasad S, Mertz GD, Itoh A, et al. Concomitant aortic valve procedures in patients undergoing implantation of continuousflow LVADs: an INTERMACS database analysis. J Heart Lung Transplant. 2015;34:797-805.

5. Feldman D, Pamboukian SV, Teuteberg JJ, Birks E, Lietz K, Moore SA, et al. The 2013 International Society for Heart and Lung Transplantation Guidelines for mechanical circulatory support: executive summary. J Heart Lung Transplant. 2013; 32:157-87.

6. Tanaka Y, Nakajima T, Fischer I, Kotkar K, Moon MR, Damiano RJ Jr, et al. The impact of uncorrected mild aortic insufficiency at the time of left ventricular assist device implantation. J Thorac Cardiovasc Surg. 2020;160:1490-500.e3.

\section{See Article page 1490.}

\section{Commentary: Stop the leak before it floods}

\author{
Bryan A. Whitson, MD, PhD
}

As our collective experience in the management of continuous flow left ventricular assist devices (CF-LVADs) matures, we are identifying that clinical entities that were previously believed to be unimportant are indeed very important. Perhaps not at the immediate time of surgical invention, although over time. This is a benefit that we have as surgeon-scientists and clinical investigators in following our patients longitudinally to track their long-term outcomes and improve the quality of our care.

Tanaka and colleagues ${ }^{1}$ provide their longitudinal experience of following LVAD patients for more than a dozen years to provide insights into the influence of uncorrected mild aortic insufficiency (AI) and the progression of heart failure. What we have known for a while is that moderate

From the Division of Cardiac Surgery, Department of Surgery, The Ohio State University Medical Center, Columbus, Ohio.

Disclosures: The author reported no conflicts of interest.

The Journal policy requires editors and reviewers to disclose conflicts of interest and to decline handling or reviewing manuscripts for which they may have a conflict of interest. The editors and reviewers of this article have no conflicts of interest.

Received for publication April 16, 2020; accepted for publication April 17, 2020; available ahead of print May 4, 2020.

Address for reprints: Bryan A. Whitson, MD, PhD, Division of Cardiac Surgery, Department of Surgery, The Ohio State University Medical Center, N-816 Doan Hall, 410 W 10th Ave, Columbus, OH 43210 (E-mail: bryan.whitson@osumc. edu).

J Thorac Cardiovasc Surg 2020;160:1502-3

$0022-5223 / \$ 36.00$

Copyright $₫ 2020$ Published by Elsevier Inc. on behalf of The American Association for Thoracic Surgery

https://doi.org/10.1016/j.jtcvs.2020.04.071

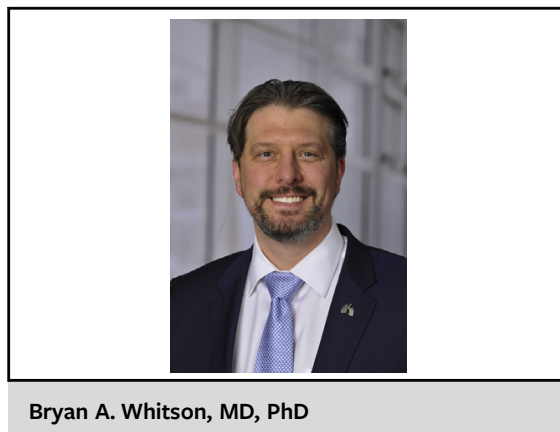

CENTRAL MESSAGE

Tracking the influence of seemingly

minor items and continuously re-

assessing our surgical approaches,

mantras, and outcomes are what

enable us to evolve our techniques

and improve outcomes for our

patients.

to severe AI in CF-LVADs portends a worse clinical outcome in terms of heart failure admissions and overall survival. $^{2}$ The progression of the AI with the CF-LVAD has been hypothesized to be related to turbulent blood flow in the root, ${ }^{3}$ potentially associated with outflow graft location and angle of anastomosis. Recognizing the importance of the influence of moderate to severe AI on CF-LVAD outcomes has led to most addressing the AI by repairing the aortic valve with a central coaptation stitch (ie, Park's stitch) or aortic valve replacement with reasonably equivalent results. ${ }^{4}$ Due to concerns related to 